\title{
LIFECYCLE PERFORMANCE MEASUREMENT OF PUBLIC-PRIVATE PARTNERSHIPS: A CASE STUDY IN CHINA'S WATER SECTOR
}

\author{
Fengyu BAO ${ }^{1,2}$, Igor MARTEK ${ }^{3}$, Chuan $\mathrm{CHEN}^{4, *}$, Albert P. C. $\mathrm{CHAN}^{1}$, Yao YU ${ }^{4}$ \\ ${ }^{1}$ Department of Building and Real Estate, The Hong Kong Polytechnic University, Hung Hom, Kowloon, \\ Hong Kong, China \\ ${ }^{2}$ Institute for Disaster Management and Reconstruction, Sichuan University, Chengdu, Sichuan, China \\ ${ }^{3}$ School of Architecture and Built Environment, Deakin University, Geelong, VIC 3220, Australia \\ ${ }^{4}$ Business School, Sichuan University, Chengdu, Sichuan, China
}

Received 28 December 2017; accepted 26 July 2018

\begin{abstract}
Numerous public-private partnership (PPP) infrastructure projects have been operating in China after nearly 30 years of development. Surprisingly, few lessons and experiences have been drawn from these existing cases, thereby creating an urgent demand for a comprehensive evaluation of their performance. Thus, this paper presents a timely contribution to the assessment of a representative PPP project in China's water sector, the Chengdu No. 6 Water Plant B Project, from a lifecycle perspective. Through a triangulation method, the project is generally deemed a success providing instructive lessons on the future evolutionary development of PPPs in China despite several imperfections caused by particular historical factors. Moreover, this paper advances the performance measurement of PPPs offering empirical insights to promote the efficacy of conceptual performance measurement frameworks. The outcomes of this research are especially valuable to the current Chinese PPP community where huge opportunities and challenges simultaneously exist.
\end{abstract}

Keywords: public-private partnership, water sector, lifecycle performance measurement, China, case study.

\section{Introduction}

The concept of public-private partnerships (PPPs) can be defined as long period co-operation between public and private sectors to jointly provide public products or services to which the risks, costs and resources related are shared by the two sectors (Ham \& Koppenjan, 2001). The PPP concept has been utilized in China over 30 years now. Despite the inconsistent development of PPPs, the total number of PPP projects initiated has considerably expanded as national policies have been repeatedly revised. According to the World Bank's Private Participation in Infrastructure (PPI) Database, the total number of PPI projects in China that have achieved financial closure as of July 2017 , is a significant 1,373 . Even so, this number does not include projects initiated by state-owned enterprises (SOEs) who are in fact major investors in Chinese PPP projects. Consequently, the actual number of PPP projects is far higher than that indicated by the PPI Database. In reality, the total number has been estimated to be as high as 7,000 to 8,000 (Dayue Consulting, 2014).
Such a large scale indicates that various participants of PPPs in China believe that the purported benefits of PPPs, such as value for money (VfM) and improved service provision, can be realized (Leiringer \& Schweber, 2010). However, these benefits were mainly claimed by government documentations and industry reports related to PPPs (e.g. PricewaterhouseCoopers, 2010; HM Treasury, 2008), whereas a number of research articles have emphasized that PPP performance practically remains unclear (Holmes, Capper, \& Hudson, 2006; Robinson \& Scott, 2009; Henjewele, Sun, \& Fewings, 2014). Thus, the actual performance of PPPs is deemed a continuing topic of debate. The reasons for the difficulty in accurately evaluating PPP performance may vary, of which, the complexity of performance concept per se could be one. Performance consists of more than "results" or "outcomes" that are suggested by some policy-makers, but is multiplication of concepts and measures (e.g. inputs, outputs, outcomes, efficiency, and process etc.) (Talbot, 2010). This complexity has frequently led to challenge of knowing what happens to most of the factors as simply as assessing

${ }^{*}$ Corresponding author. E-mail: chenchuan.scu@qq.com 
the "outputs" or "results". For PPPs, the issue is further compounded by the intricate nature of the PPP mode which inevitably weakens the effectiveness of most existing performance measurement means designed for normal business process (Liu, Love, Smith, Regan, \& Palaneeswaran, 2015b).

The situation in Chinas PPP domain, where the continuing immaturity of its environment for developing PPPs remains, is no exception and probably even more critical. A few critics even stressed that China's overinvestment in unproductive PPPs has given rise to many problems, such as rising debts, unstable financial market, and fragile economy (Ansar, Flyvbjerg, Budzier, \& Lunn, 2016). Determining the actual performance of PPPs in China, and drawing lessons and experiences from prior cases are extremely important. Such processes would provide crucial basis for improving PPP management strategies and facilitating sustainable development of PPPs in the future.

This research aims to fill this gap by conducting an empirical study on the performance measurement of PPPs. In particular, this research considers the case of the Chengdu No. 6 water plant B project (hereinafter referred to as the Chengdu Project) to investigate its lifecycle performance. Using lifecycle of the Chengdu Project as the unit of analysis is mainly because the lifecycle philosophy is vital for PPP projects requiring integrated duties on design, finance, construction and maintenance (EIB, 2012). Essentially, VfM is recognized as the paramount objective of PPP, which cannot be defined, let al.ne to be achieved, without a lifecycle perspective (HM Treasury, 2004). Notably, the Chengdu Project was the first PPP project in the Chinese water sector and the only one having gone through the entire concession period in this sector. A triangulation method was employed to collect and analyze data, comprising literature review, archival analysis, structured questionnaire survey and a post-survey interview. The specific research objectives include the following:

- Evaluating the lifecycle performance of the representative project;

- Identifying project lessons and experiences and interpreting dissent from lifecycle and historical perspectives; and

- Proposing constructive implications for future development of water PPPs in China as well as for future research on PPP performance measurement.

Consequently, practitioners in the field of PPP water projects will be interested to obtain the lessons and experiences extracted from this project as evaluated over its entire lifecycle. Thus, the findings are particularly helpful to PPP participants in pursuing lifecycle success of PPPs in developing countries. Moreover, the research outcomes would contribute to the ongoing research on PPP performance measurement by providing empirical insights into the improvement of those conceptual findings.

The next section briefly reviews the application of the PPP approach in China's water sector and the literature on performance measurement of PPPs, followed by methodology, background of the Chengdu Project, data analysis and findings, discussion, and conclusions.

\section{Literature review}

\subsection{Performance debate of PPPs}

As previously mentioned, the benefits of PPPs have been vigorously propagandized by governments which lack the access to funds and capability to provide public infrastructures and services. Many documentations and reports from governments or their client agencies repeatedly claimed the positive performance of PPPs. For example, the Victoria State Government (2017) claimed that PPPs benefited this state by providing "world-class" infrastructure and public services for over 20 years. As the initiator of private finance initiative (PFI), one of the counterparts of PPPs, the UK governments maintained the continuous promotion and practice of this approach since 1992 (HM Treasury, 2013b; HM Treasury, 2013a; HM Treasury, 2016). The positive performance of PPPs can also be seen in a few guide references compiled by international cooperation organizations such as the World Bank, European Investment Bank (EIB), and Asian Development Bank (ADB), which further spread the popularity of PPPs worldwide (World Bank, 2014; EIB, 2012; ADB, 2008). Consequently, various practitioners have trusted this view and taken PPPs as the main, if not the only, methods to develop public infrastructure and services, just as what China's water sector has experienced in the past two decades.

However, questions and criticisms of the purported benefits of PPPs have been also constant (Hodge, 2004). Holmes et al. (2006) investigated the health care PFI in the UK and argued the difficulty of demonstrating VfM because of the uniqueness of each PPP project. Henjewele et al. (2014) compared health care and transport PPPs and then concluded that considerable cost and time overruns and changes still existed in the development process of PPPs. Pollock, Price, and Player (2007) investigated five studies cited by the UK's Treasury as support to its positive claim of PPPs and found that only one study compared PFI and traditional procurement, in which sampling bias and flawed analysis extremely weakened conclusion to be supportive to the Treasury's claim. Hodge and Greve (2007) summarized manifold possible reasons for the contradictory evidence delivered by PPP performance evaluations. As for China, Ansar et al. (2016) examined the PPP performance in its transport sector and found severe cost overruns and benefit deficiencies. Despite having investigated many sectors on their performance of PPPs, the attention paid to the water sector was found to remain scarce. Most prior research has focused on developed economies where PPP model is not the chief means for water projects (Hall, Lobina, \& Terhorst, 2013). However, this scenario is not the case for developing countries, such as China, where numerous water PPPs exist. Thus, for those developing countries, an urgent need consequently arises to establish a systematic investigation of the performance of water PPPs. 


\subsection{Application of PPPs in China's water sector}

The water sector (i.e., water supply and sewage treatment) accounts for the largest proportion among China's various PPP infrastructure sectors. Cheng, Ke, Lin, Yang, and Cai (2016) analyzed all the current PPP projects in China, which are identifiable through the internet; authors then claimed that water projects account for $54.6 \%$ of all the projects. Although large, the proportion is explicable since water projects are in high demand, tend to have stable returns, and require only a relatively small investment, with a correspondingly low investment risk. Indeed, the water sector was where one of the three pilot PPP attempts was initiated by the central government, back in the mid-1990s, consequently providing a precedent by which foreign and private investors found access to the market (Cheng et al., 2016). And yet, despite the number of projects to date, China's urbanization remains far from complete. In the near future, a growing number of people will move into cities, implying that the demand for water infrastructure will remain undiminished. Thus, opportunities for investing in the Chinese water sector through PPPs can be expected to remain strong.

The Chengdu Project is one of the most well-known among existing PPP water projects, its renown lies in a couple of factors. First, it is the first municipal water supply project built in the form of Build-Operate-Transfer (BOT) in China. Second, it was regarded as a highly successful case; being awarded the "Best Project Financing Deal of the Year" award, in 1999, by "International Project Finance." Still, it has also been subject to severe criticism due to its negative impact on several other bodies, such as the water company and the government of Chengdu. Despite mixed reviews, the Chengdu Project is a representative test case benchmarked by numerous later projects in Chinese water sector over the past two decades. Thus, the lessons and experiences drawn from this project can be expected to offer valuable insights for future PPP applications in China.

\subsection{Performance measurement framework of PPPs}

Performance measurement is generally defined as a process in which organizations or individuals determine the extent of their success in reaching their desired objectives after a series of management actions (Neely, Adams, \& Kennerley, 2002; Kagioglou, Cooper, \& Aouad, 2001; Bititci, Carrie, \& McDevitt, 1997). It is viewed as a revolution in management, deriving from the business area and having extensively spread out to other industries (Bassioni, Price, \& Hassan, 2004; Neely, 1999). In the construction industry, performance was once mainly represented by several factors, such as cost, time, and quality, which were soon found insufficient to comprehensively describe a complex construction project (Kagioglou et al. 2001; Ward, Curtis, \& Chapman, 1991). Consequently, certain performance measurement frameworks, which comprise a set of indicators or measures, have been formed and adopted in the construction industry. Yang, Yeung, A. P. C. Chan, Chiang, and D. W. M. Chan (2010) summarized three frequently applied categories of frameworks, namely, (1) European Foundation for Quality Management (EFQM) excellence model; (2) Balanced Scorecard (BSC) model; and (3) Key Performance Indicators (KPIs) model.

The abovementioned three frameworks have varied application levels, despite the absence of absolute difference in their capability to evaluate a project (Liu et al., 2015b; Yang et al., 2010). Performance measurement commonly refers to three levels, namely, (1) project, (2) organizational, and (3) stakeholder levels (Yang et al., 2010). The EFQM model is suitable to project and organizational levels; the BSC model focuses on organizational level; and the KPIs model is the only one applicable among all the three levels (Yang et al., 2010).

To measure PPP performance, Liu et al. (2015b) critically reviewed relevant research and surprisingly found that, even in countries with a mature PPP system, many PPP projects were not comprehensively monitored or evaluated in terms of their implementation, which resulted in problems with the delivery of PPPs in different sectors. Noticeably, most current performance measurement methods were considerably simplified in practice, ignoring many significant aspects when describing the success of PPPs (Liu et al., 2015b). The difficulty in measuring the performance of PPPs is understandable as their execution intricately involves multiple stakeholders with significant conflicts of interest and varied phases unlike one another in terms of characteristics and tasks (EIB, 2012). To deal with this complexity, some latest studies in PPP domain suggested multiple evaluation perspectives, including phase (lifecycle)-based perspective, as well as stakeholder and process-based perspectives (Liyanage \& VillalbaRomero, 2015; Liu, Love, Davis, Smith, \& Regan, 2015a; Yuan, Yajun Zeng, Skibniewski, \& Qiming, 2009; Liu et al., 2016). Thus, considering the need to focus on multiple levels of performance, these studies mainly adopted the KPIs model as the performance measurement framework.

Following the precedent, this research adopts the KPIs model as its framework, and the next sub-section forms the conceptual framework by reviewing significant indicators used in the literature.

\subsection{Conceptual framework}

\subsubsection{Phase-based perspective}

A phase-by-phase evaluation can compartmentalize the performance measurement into digestible portions and is particularly useful for PPPs with long lifecycles (Liu, Love, Smith, Matthews, \& Sing, 2016). Each phase involves different stakeholders and procedures, leading to varying criteria for performance measurement. In China, the Ministry of Finance (MoF) (2014) divides the development process of PPPs into five phases, namely, project identification, project preparation, project procurement, project implementation, and project transfer. Among these phases, the first three have previously been analyzed by prior researchers. Particularly, Chen (2009) also utilized the Chengdu Project as case for analysis. However, 
the two remaining phases still lack empirical evidence to demonstrate their performance in practice.

\subsubsection{Stakeholder indicators}

Generally, PPP stakeholders are individuals or organizations that have either an impact on or are impacted by project development (El-Gohary, Osman, \& El-Diraby, 2006). Three indicators regarding stakeholders were frequently considered, namely, stakeholder satisfaction, contribution, and capabilities. Stakeholder satisfaction is particularly important in evaluating PPP performance as each stakeholder has unique expectations on the PPP outcome (Liu et al., 2015a). For example, a government is actively involved in a water PPP probably as it aims to fill the existing water demand gap in its city. Although a private party is willing to bear the responsibility of providing quality water that would fulfill the government's goals, its primary motif is the pursuit of profit. Both parties' satisfaction must be met over the lifecycle of the project. Stakeholder contribution is in conflict with satisfaction (Liu et al., 2015a). Whereas the satisfaction indicator denotes the expectation of a particular stakeholder from a PPP, the contribution indicator denotes the requirement of that stakeholder to achieve a successful PPP, as estimated by other stakeholders. Stakeholder capabilities refer to necessary skills, technologies, and practical experiences which are necessary to operate a business process (Neely et al., 2002). This indicator must be evaluated as it reveals whether the competitiveness of a stakeholder is sufficient to the task to be performed (Neely, Adams, \& Crowe, 2001).

\subsubsection{Process indicators}

In achieving PPP success, the business processes within each phase must be grouped appropriately (Liu et al., 2015a). Therefore the process effectiveness of each phase should also be measured. A series of process indicators were emphasized by Hodge (2004), Liu et al. (2015a), Osei-Kyei, Chan, Javed, and Ameyaw (2017), and Yuan et al. (2009) (see Table 1).

Table 1. Process indicators used for the evaluation

\begin{tabular}{|c|l|c|}
\hline Code & \multicolumn{1}{|c|}{ Indicator } & Source \\
\hline I1 & TCQ (Time, cost and quality) management & $1,2,3$ \\
\hline I2 & Health, safety \& environment impact & $1,2,3$ \\
\hline I3 & Risk management & $1,3,4$ \\
\hline I4 & Facility management & 1,2 \\
\hline I5 & Dispute management & $1,2,3$ \\
\hline I6 & Profitability & 2,3 \\
\hline I7 & Contract management & 1,2 \\
\hline I8 & Local economic development & 3 \\
\hline I9 & Reliable product operation & $1,2,3$ \\
\hline I10 & Technology transfer & 3 \\
\hline I11 & Compliance of legal and regulatory framework & 2 \\
\hline I12 & Public administrative cost & 3 \\
\hline
\end{tabular}

Note: 1 - Yuan et al. (2009); 2 - Liu et al. (2015a); 3 - Osei-Kyei et al. (2017); 4 - Hodge (2004).
The construction of PPP infrastructure is important, with project assets expected to last for some decades. Consequently, the process effectiveness can first be evaluated using traditional indicators that were widely used in the construction industry. These include such measures as TCQ management, and, health, safety and environment impact (A. P. C. Chan \& A. P. L. Chan, 2004; Atkinson, 1999). However, given the additional unique features of PPPs, such as multiple stakeholders, an emphasis on risk allocation, complex contract structures, and reduced public costs (World Bank, 2014; EIB, 2012), additional nontraditional measures require consideration. Thus, these measures, including effective risk management, dispute management, contract management, and reduced public administrative costs, must also be studied to measure the process effectiveness.

In PPPs, the private sector is required to assume the majority of the responsibilities, not only during construction but also in operating and maintaining the project assets. However, such role is compensated with opportunity to earn reasonable profit during the concession period. Consequently, the facility management, profitability, and reliability of operations also require analysis. In developing countries, such as China, PPPs are also expected to facilitate the promotion of the local economy and the acquisition of technology. Therefore, local economic development and technology transfer should also be investigated. What is more, the legal and regulatory framework for PPP applications significantly varies from country to country, resulting in the necessity to evaluate PPP's compliance with the local legal and regulatory framework.

\section{Background of the Chengdu project}

The Chengdu Project lies in Chengdu city, Sichuan province, China. By the end of the 1990s, the daily demand for water in Chengdu had risen to 1.3 million $\mathrm{m}^{3}$, yet water actual supply could only provide 1.053 million $\mathrm{m}^{3}$. This left a significant shortfall of some $250,000 \mathrm{~m}^{3}$ (People's Daily Online, 2000). The situation was made worse when contamination further reduced water production of existing Chengdu plants (Chen \& Doloi, 2008). To assuage the water crisis, the Chengdu municipal government (CMG) initiated a new water plant development program that proposed several projects. Of these, the Chengdu Project was the only one that adopted a PPP model. It was initiated in 1993 as a traditional water project but was hastily suspended due to financing difficulties. The project was then revitalized in 1996 under the "National Experimental BOT Program," initiated by the central government. An international open bid was held that year and ultimately, Compagnie Génénerale des Eaux Group (currently Veolia Group), France, and the Marubeni Corporation, Japan were granted the concession. Subsequently, the Chengdu Génénerale des Eaux-Marubeni Waterworks Co., Ltd. (CGMW) was established as the project company, and it began immediate work on the project. The concession 
period was to be 18 years, including 2.5 years for construction, with 17.5 years for operation. Actual commercial operation began in 2001, with treated water was delivered to the Chengdu Waterworks General Company (CWGC), a local state-owned utility. Upon expiry of the 18-year concession period, the plant transferred to the CMG, with transfer having taken place on 10 August 2017. Table 2 summarizes the main features of the Chengdu Project.

The Chengdu Project has nine key identifiable stakeholders; one more than the eight identified by Liu et al. (2015a). They are: public client, shareholders, creditors, general concession contractor, subcontractors, suppliers, employees, and end-users. The additional stakeholder here is the Xingrong Group, which is a state-owned enterprise that was designated by CMG as the transferee taking over the project after transfer. The complete list of the stakeholders of the Chengdu Project is presented in Table 3.

As the first official PPP project undertaken in China's water sector, the Chengdu Project was expected to provide an exemplary precedent for the future development of the Chinese water market, and in so doing, attract further international and private investment (Chen \& Doloi, 2008). As the first project of its kind, it also attracted the attention of industry and academia, alike. Notably, Chen (2009) comprehensively reviewed the development process of the Chengdu Project, including contract structure, and the risk allocation and roles of the main stakeholders. Six factors were identified as impacting the re-applicability of the project. These were: (1) the flagship status of the project; (2) that local government bore relatively more of the risks and responsibilities; (3) that lenders participated in the project development process; (4) the localization of material procurement for construction and maintenance;

Table 2. Summary profile of the Chengdu No. 6 Water Plant B Project

\begin{tabular}{|l|l|}
\hline PPP model & Build Operate Transfer (BOT) \\
\hline Financial closure year & 1999 \\
\hline Project contents & $\begin{array}{l}\text { A water plant, water intake } \\
\text { facilities, a 1,030-m discharge } \\
\text { pipeline, and a 27-km } \\
\text { water transmission pipeline } \\
\text { (DN2400 mm) linking the } \\
\text { water plant to the urban water } \\
\text { distribution network. }\end{array}$ \\
\hline $\begin{array}{l}\text { Capacity of the water } \\
\text { plant }\left(1000 \mathrm{~m}^{3} / \text { day) }\right.\end{array}$ & 400 \\
\hline Total investment (US\$ M) & 106.5 (32 as equity +74.5 as debt) \\
\hline Contract term (years) & 18 \\
\hline Sponsors & $\begin{array}{l}\text { Veolia (contributing } 60 \% \text { of equity) } \\
\text { Marubeni (contributing } 40 \% \text { of } \\
\text { equity) }\end{array}$ \\
\hline Lenders & $\begin{array}{l}\text { ADB (contributing } \$ 48 \text { million } \\
\text { of debt) } \\
\text { EIB (contributing \$26.5 million } \\
\text { of debt) }\end{array}$ \\
\hline
\end{tabular}

Note: ADB - Asia Development Bank; EIB - European Investment Bank.
Table 3. Stakeholders of the Chengdu No. 6 Water Plant B Project

\begin{tabular}{|l|l|}
\hline Public client & $\begin{array}{l}\text { CMG } \\
\text { CWGC }\end{array}$ \\
\hline Shareholders & $\begin{array}{l}\text { Veolia Group } \\
\text { Marubeni Corporation }\end{array}$ \\
\hline Creditors & $\begin{array}{l}\text { ADB } \\
\text { EIB }\end{array}$ \\
\hline $\begin{array}{l}\text { General concession } \\
\text { contractor }\end{array}$ & CGMW \\
\hline Subcontractors & $\begin{array}{l}\text { Campenon Bernard-SGE } \\
\text { Omnium de Traitements et de } \\
\text { Valorisation } \\
\text { SADE Compagnie Generale de Travaux } \\
\text { d'Hydraulique }\end{array}$ \\
\hline Suppliers & 50 percent local companies \\
\hline Employees & All Chinese \\
\hline End-users & Residents in Chengdu \\
\hline Transferee & Xingrong Group \\
\hline
\end{tabular}

(5) the adoption of reliable and economical technology; and (6) the complicated approval procedure and timeconsuming development process. Chen concluded that the Chengdu Project could provide an important benchmark but could not be adopted as a template for future water projects.

Nevertheless, the Chengdu Project triggered a surge in PPP water projects throughout China. Its contractual structure and risk allocation scheme, for example, have been duplicated across numerous water supply plant projects. Yet, as mentioned previously, this project was not without its critics, with many experts and scholars questioning the effectiveness of the PPP model adopted. With the Chengdu Project now transferred back to the CMG, the moment is right to revisit the project and reassess its effectiveness and document its lessons.

This paper continues the evaluation by picking up where Chen left off, and explores the remaining two phases, i.e. the project implementation and transfer phase. However, considering that the implementation phase in fact comprises a construction and operation stage that are totally differ from each other in terms of procedures and deliverables, in this paper these are examined separately. That is to say, in this paper, the Chengdu Project is examined across the final three stages of construction, operation and transfer.

\section{Methodology}

\subsection{Research design}

This paper adopted case study as the main research methodology. Case study is deemed suitable and effective in facilitating practitioners' acquisition of lessons and experiences from the best practices extracted (Zhang, Chan, Feng, Duan, \& Ke, 2016), which is also the objective of this paper. Besides, PPP projects in certain 
circumstances frequently have unique characteristics, thereby considerably challenging the adoption of existing knowledge focusing on places with different contexts (Cruz, Marques, \& Pereira, 2015). This feature causes the development of PPPs a highly complicated, projectspecific process. To increase PPP success under a particular circumstance, an in-depth analysis of cases under the same circumstance could be much helpful (Zhang et al., 2016). Thus, a considerable amount of previous research has utilized case study as a method to investigate diverse PPP topics (e.g. (Wu, Liu, Jin, \& Sing, 2016; Sobhiyah, Bemanian, \& Kashtiban, 2009; Chen, 2009; Jefferies, 2006; Şentürk, Yazici, \& Kaplanoğlu, 2004; Wang \& Tiong, 2000; Tiong, 1990)), which proved its suitability in PPP area. Especially in China, case study has emerged as the most popular research method adopted by PPP researchers from 2005 to 2014 (Zhang et al., 2016).

This paper employed a crucial case study method (Gerring, 2007), that is, a single case, the Chengdu Project, was selected as research object for the following reasons: (1) this paper aims to establish an authentic revelation of the lifecycle performance of China's water PPPs; thus, cases that underwent the entire concession period could be suitable. The Chengdu Project remains to be the only water PPP with that accomplishment in China; (2) the Chengdu Project is also the first official BOT project in Chinese water sector; as mentioned earlier, many significant aspects, such as governance structure, risk allocation and payment mechanism, have been duplicated by most, if not all, of the subsequent water PPPs in China (Chen, 2009). Therefore, this case is a representative of numerous water PPPs, and insights from which could benefit the management of all those projects; and (3) a trend exists in PPP area to use single typical project as a case to gain empirical knowledge (Wang, Tiong, Ting, Chew, \& Ashley, 1998; Cheung \& Chan, 2009; Shen, Platten, \& Deng, 2006).

In particular, a triangulation method was adopted to perform case analysis, including the following four crosschecking approaches: literature review, archival analysis, questionnaire survey, and post-survey interview. First, a literature review was conducted to identify established PPP performance indicators. This was followed by a structured questionnaire survey of key stakeholders who have experienced Chengdu Project over its lifecycle. A post-survey interview was then conducted to provide respondents a chance to elaborate their evaluation of those indicators. Additionally, an in-depth archival analysis was also conducted to corroborate and augment findings from the prior procedures. Final conclusions were drawn after the triangulation and verification of the outcomes from these various sources. Figure 1 summarizes the overall research design.

\subsection{Collection of data}

Figure 2 illustrates the various data collection methods. A wide range of archival data regarding the Chengdu Project have been collected from inception to completion. These

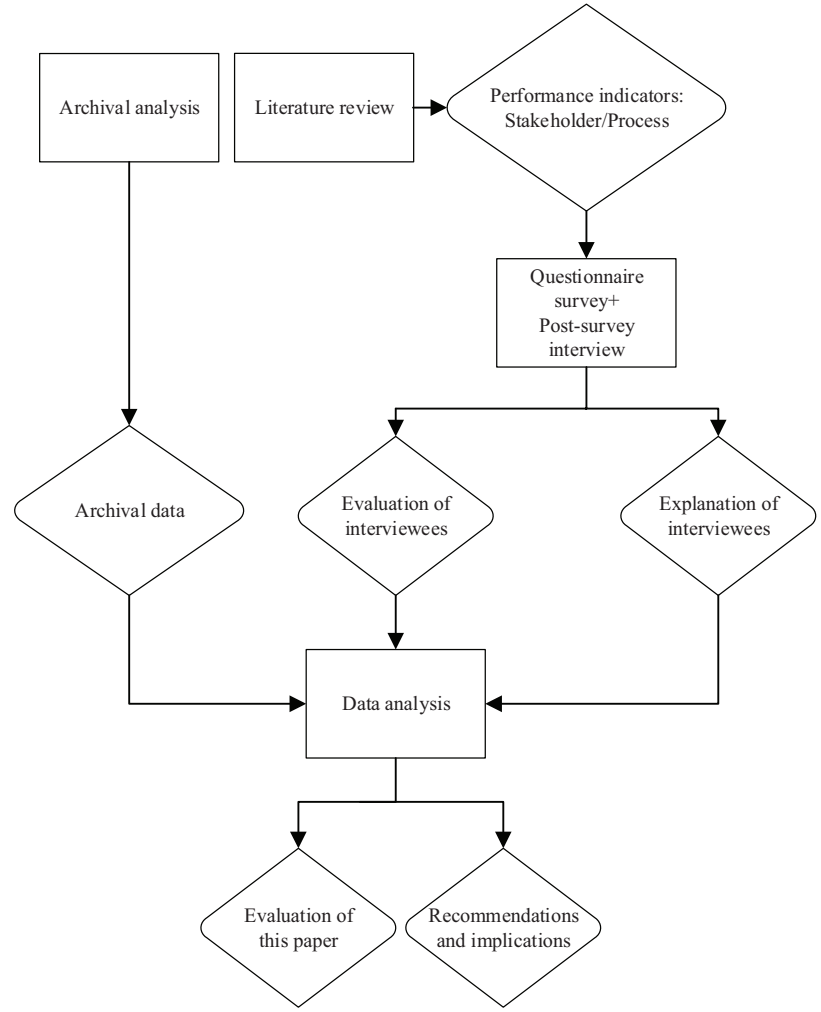

Figure 1. Research design

data cover the economic, financial, technical, legal, and environmental aspects of the project, including the project proposal, government directives, feasibility study report, bidding documents, contract documents, financial records, safety records, QA and QC files, project completion reports, environmental appraisal reports, interim performance check reports, audit reports, and media news and reports. The archival data revealed key performance data, such as TCQ of construction, volume of water produced, water quality, and the project's financial condition.

To cross-check the archival data, and to augment any missing information that may be pertinent to the performance aspects of the project, questionnaire surveys and post-survey interviews with key stakeholders of the project were carried out. The questionnaire consists of questions asking respondents to evaluate the overall performance and performance indicators identified from literature (refer to section 1.4) across each phase of the project. Structured questions were tailored, contingent upon the role of the respondents. Specifically, in line with ADB (2006), the respondents were asked to rate items to be assessed according to discrete criteria, namely, unsuccessful, partly successful, successful, or highly successful. The ratings from unsuccessful to highly successful were translated into numbers from zero to three; subsequently, the mean value for each indicator was calculated for statistical analysis (ADB, 2006). After completing the questionnaire survey, the post-survey interview was immediately conducted to pursue explanations and clarifications regarding particular rating items; and hopefully to solicit a wideranging data pertaining to the project (e.g. respondents' 


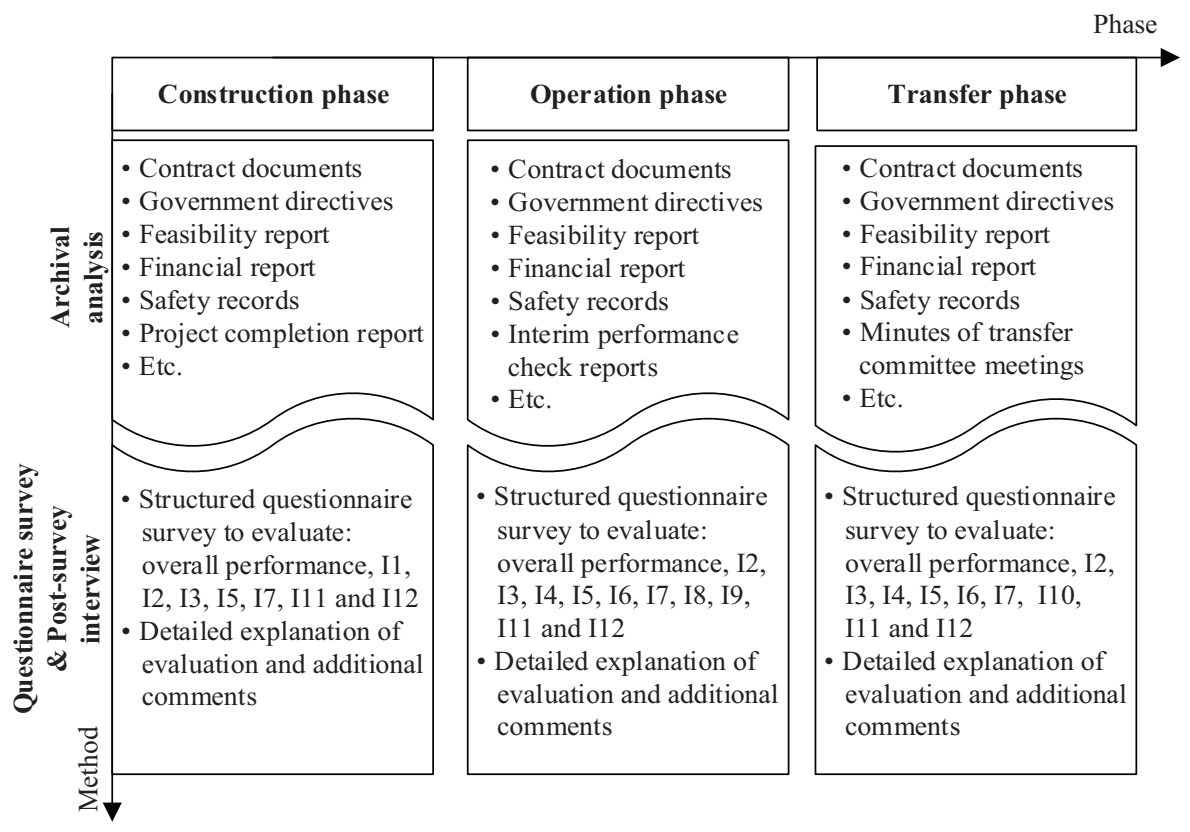

Figure 2. Data collection methods

complementary comments toward the project). Audio records of post-survey interview were then transformed into an interview transcript that was further processed through thematic analysis to extract both manifest and latent information regarding the performance evaluation of the project (Vaismoradi, Turunen, \& Bondas, 2013). Each respondent was given a code to facilitate the revisit of the data as the analysis was conducted.

To ensure the comprehensiveness and authoritativeness of the data garnered, respondents who meet two criteria were considered, that is, (1) having experienced the project over its entire lifecycle and (2) representing distinct roles in managing the project. That is, the purposive sampling technique was adopted for data collection. The purposive sampling is believed as the most effective way to extract insights from experienced experts (Chan et al., 2017). Given that the project has been operational for almost 20 years, identifying respondents who met this required familiarity with the project over this lengthy period proved difficult. The operator, CGMW, was believed to possess most knowledge on the project as it had been operating the plant for nearly 20 years. Therefore, the connection with the core management members of CGMW was built first through personal relationship. Through them as well as other personal channels of the authors, slowly building connections happened with other significant stakeholders, such as Veolia, CMG, and CWGC. Surveys were conducted on four occasions (i.e. 3 August 2015, 20 February 2016, 9 May 2016 and 9 May 2017). Ultimately, a total of 12 respondents partook in the study. Among these participants, nine were senior management representatives from the public and private sectors, and the other three were end-user, residents, and water users (see Table 4). All respondents had close and long
Table 4. Respondents' profile

\begin{tabular}{|l|c|c|}
\hline \multicolumn{1}{|c|}{ Sectors } & $\begin{array}{c}\text { No. of } \\
\text { respondents }\end{array}$ & Percentage (\%) \\
\hline Government & 2 & 17 \\
\hline CGMW & 4 & 33 \\
\hline Veolia & 1 & 8 \\
\hline CWGC & 2 & 17 \\
\hline Local residents & 1 & 8 \\
\hline End-users & 2 & 17 \\
\hline Total & 12 & 100 \\
\hline
\end{tabular}

connections with the Chengdu Project and possessed profound familiarity and understanding on it, based on their respective roles. Considering the strict criteria of choosing respondents and the narrow scope for sampling, this number of respondents was acceptable. Additionally, since evaluating an actual PPP project seems sensitive to many practitioners in China, the manner of approaching the senior management members from distinct stakeholders (i.e. using private relationship) was practicable and efficient.

\section{Findings and analysis}

Several stakeholders were not represented in the survey process. These included the creditors, subcontractors, suppliers, and transferee. Compared with the primary stakeholders interviewed, their relationship with the Chengdu Project was comparatively shorter and significantly weaker involving far less complicated responsibilities. Thus, their performance may be evaluated sufficiently from relevant archival data. The archives confirm that they all achieved their principal objectives through the project. The credi- 
tors, $\mathrm{ADB}$ and $\mathrm{EIB}$, engaged in the project from as early as the preparation stage, with the purpose of promoting infrastructure development in China and recovering the loan and interest, which were achieved through the project operation. Similarly, the subcontractors, suppliers and transferee all attained their expectations of the project by actively carrying on duties required by the contracts.

Nine of the respondents, those from the public (i.e. CMG and CWGC) and private sectors (i.e. Veolia and CGMW) completed the entire survey and post-survey interview; whereas the remaining three, one local resident along with two end-users, could offer only limited evaluation because they lacked exposure to the development process of the project. Therefore, statistical analysis was based on the completed feedback of the nine respondents. The statistical results were then verified by using archival data to improve the objectivity of the findings. The following sections present the research findings and analysis from the phase-based perspective.

\subsection{Project construction}

On 10 September 1999, 20 days after financial settlement, CGMW convened representatives of the project construction contractors for the first regular meeting. This step signaled the practical start of the project construction phase. The entire construction phase lasted for 29 months, with the following three stages: preparation (five months from September 1999 to January 2000), construction (23 months from February 2000 to December 2001), and commissioning stages (one month from January to February 2002).

The public and private sectors had a rather positive evaluation of the Chengdu Project's construction, awarding 2.5 and 3.0 to the overall evaluation, respectively (see Figure 3 ). All the respondents agreed that the TCQ of construction was achieved in a high level of success. This result was expected because the awarding process was open and fair, ensuring that the international procurement and subcontracting processes guaranteed the abilities of the concessionaire, contractors, and subcontractors. Given a strong aspiration for a desirable construction outcome, all participants fully contributed to the project construction phase. In general, the construction phase was very successful as seen from the key stakeholders' perspective.

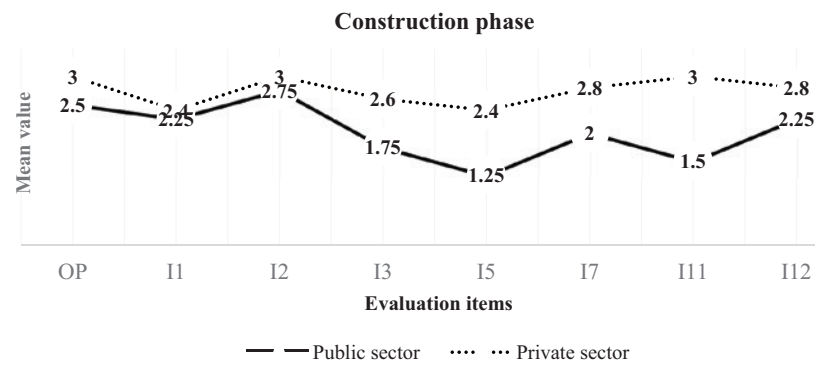

Figure 3. Mean values of the evaluation on project construction phase

Note: OP - Overall performance
Seven process indicators were evaluated in the construction phase (see Figure 3). Although both public and private sectors agreed with the successes of I1, I2 and I12, they held varying opinions on the remaining four indicators. Of these remaining four, CGMW held a highly positive evaluation; however, the public sector expressed a divergent, lower satisfaction with them. This can be seen in Figure 3, as I5 (1.25), I1 1 (1.5) and I3 (1.75). Dispute management or I5 stands out as having the lowest evaluation of the public sector. One technology expert from CWGC (referred to as CWGC 1) explained that such judgment was mainly due to the disputes during the construction stage that frequently ended with a significant compromise from the public sector. To support this point, CWGC 1 provided a few examples:

Out of cost considerations, CGMW proposed a 16-mm thickness for the DN2400 transformation pipeline, which was two $\mathrm{mm}$ thinner than China's $18 \mathrm{~mm}$ standard. This disparity led to negotiations between us, yet CGMW's position stood and the $16-\mathrm{mm}$ proposal was adopted at last. Moreover, there were occasions when design and construction were carried out simultaneously over the construction phase, which is contrary to Chinese construction regulations. Such compromises borne by our side directly contravened our laws, setting a very bad example to the future! What is more, reduced standards of construction increased the risk to quality as well.

(Technology expert, CWGC 1)

For these reasons, the public sector also offered relatively low ratings to I1 1 or compliance of legal and regulatory framework, and I3 or risk management.

By contrast, the private sector believed the construction of the Chengdu Project to be particularly successful, in terms of processes and outcomes. Two senior managers from CGMW and Veolia (referred to as CGMW 1 and Veolia 1, respectively) emphasized that success was guaranteed due to their rich experiences and expertise in delivering water projects:

We have much confidence in our expertise and
management systems. Indeed, the construction
of the Chengdu Project could have been com-
pleted much earlier if the government had been
more efficient in its own preparation work, like
their delays in the delivery of temporary land for
pipeline construction.

(Senior manager, CGMW 1)

As to the violations of Chinese construction standards and regulations, they defended themselves by expertise and experiences as well:

\footnotetext{
The standard we adopted had been tested and approved across many previous projects completed around the world. We insisted on our own standard because it was, in our experience, safe enough, while at the same time greatly reducing construction cost.
}

(Senior manager, Veolia 1) 


\subsection{Project operation}

At 0:00 on 11 February 2002, CGMW formally commenced the commercial operation of the Chengdu water plant. To date, the plant has been running at full capacity $\left(400,000 \mathrm{~m}^{3} /\right.$ day $)$ for over 15 years. The plant's water has been stable and uninterrupted by technical problems, despite experiencing numerous extreme events over this operational period. According to the operations record, the most common risk events totaling 17 as of 2016, concerned the reduction in quality of raw or treated water. These events were typically caused by extreme weather conditions (e.g. storm rain) or accidental events (e.g. power outage).

A senior manager from CGMW (referred to as CGMW 2) considered the greatest threat to the operation of the water plant as an example, that is, the 8.0 magnitude Wenchuan Earthquake, which occurred on 12 May 2008 and led to over 100,000 casualties in total, to show its strong emergency capacity:

\begin{abstract}
Although only $60 \mathrm{~km}$ away from the epicenter, our facilities, along with $27 \mathrm{~km}$ pipeline, suffered negligible damage. This was due to our strong seismic resistance engineering. At that time, the in-place disaster response drills proved effective. As per the contingency plan, the power department summarily switched to the backup power supply to circumvent the power outage, while the safety department immediately checked the most dangerous chlorine dosing system to ensure that no leakage had occurred. After resuming normal production, we also responded to prevent potential secondary disasters, such as flooding due to dam failure, water pollution by chemical leakage or debris washing into the river etc. that could occur at any time. We remained in close communication with the relevant departments over the duration of the crisis, making adequate arrangements for processing technology, personnel allocation and drug reserves. Moreover, in addition to the fixed water supply amount, from 21 to 28 of May 2008, we successively managed three emergency water treatment facilities to provide emergency water supply services to the most affected areas.
\end{abstract}

(Senior manager, CGMW 2)

Although the Chengdu Project has earned wide recognition for its positive handling of emergency circumstances, a range of assessments were made by the stakeholders. From the survey results, a clear distinction exists in the evaluations of the operation phase between the public and private sectors (see Figure 4). Respondents from the private party consistently expressed high satisfaction levels in the operation phase, with a perfect score, 3.0, in its overall evaluation. Whereas the score achieved from respondents representing the public side averaged a mere 1.25 , sitting between "partly successful" and "successful". Their conflicting evaluations were closely related to the different expectations to the Chengdu Project, which can be seen from their post-survey explanations.
For the private party, the key objectives were profit, and market share. A senior manager from CGMW (referred to as CGMW 3) described the achievement through the Chengdu Project:

First, stable income was successfully achieved over the 18 years' concession period. Second, and more importantly, market access into China's water sector has been gained through this project. Actually, we were awarded a successive series of further PPP contracts following the Chengdu Project, covering not only drinking water treatment but also entire water supply services, sewage treatment and industrial water operations.

(Senior manager, CGMW 3)

For the public sector, the Chengdu Project was expected to address the financial dilemma faced by the government in developing urban water infrastructure with limited investment capacity. However, the government failed to anticipate that the water demand in Chengdu did not rise as expected at the start of operations. A respondent from the government (referred to as Gov. 1) thoroughly introduced this unfortunate incident as follows:

The expected water demand did not appear; however, CWGC was required to purchase 400,000 $\mathrm{m}^{3} /$ day of treated water, according to the offtake agreement. Under these circumstances, CWGC had to shut down some other water plants in order to fulfill the contract, which turned the otherwise profitable status of CWGC into a deficit of RMB 150 million yuan, in the first year. As a result, CMG had no recourse but to offer more than 100 million in subsidies to CWGC, over the first few years.

\section{(Official, Gov. 1)}

However, the unanticipated situation also fully reflected the contribution and capability of CMG. Despite bearing a huge burden caused by the commitment to make a daily purchase of $400,000 \mathrm{~m}^{3}$ of treated water, CMG never defaulted. Meanwhile, CGWC took active measures to alleviate its financial difficulties by expanding the water network into nearby suburbs with an updated pipeline network and by gradually reforming the water price upwards to accord with market price levels. CMG's compliance with the contract highlighted its good credit standing, along with its financial capacity to manage PPPs.

From the public sector's perspective, satisfaction in the operation phase was relatively low owing to the unexpected decline in demand, whereas the responsiveness and effectiveness in handling this unexpected development were successfully achieved. In the estimation of the private party, all the three indicators were seen to have achieved a high level of success based on the criteria of stable income and continued quality water provision over the entire operation phase.

As for process indicators, the public and private sectors regarded factors I2, I4, I6, I8, I9, and I11 as successful. The mean values for these indicators were rated at 2.0 or above (Figure 4). Both sides acknowledged the profit- 


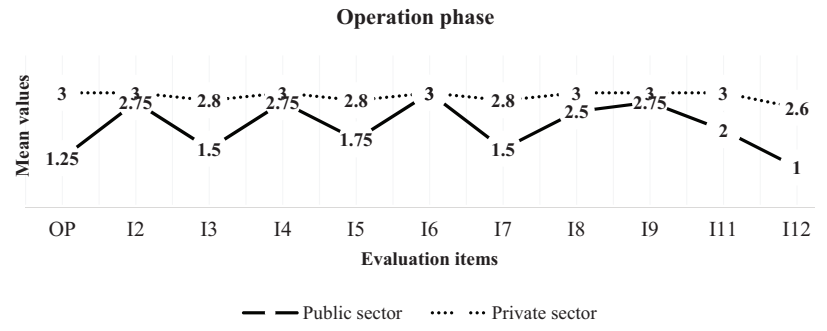

Figure 4. Mean values of the evaluation on project operation phase

Note: OP - Overall performance

ability of the plant, which is attributed principally to the stable income guaranteed by the offtake agreement. They also believed that the production process of treated water was reliable, healthy for the environment, and beneficial to the local economy. Moreover, they believed that all facilities were well maintained over the entire operation phase.

For the remaining process indicators (I3, I5, I7, and I12), the private party maintained a positive evaluation close to highly successful. Conversely, the views from the public sector diverged, with respondents inclined to choose a performance between partly successful and successful for these four indicators. In particular, they expressed least satisfaction with I12 or public administrative cost. This result was expected to be lower as a consequence of using PPP procurement instead of using traditional means of financing. One respondent from the government (referred to as Gov. 2) referred to this indicator as follows:

\begin{abstract}
The lowering of overall costs was a critical reason for us to employ PPP. However, the unexpected decline in water demand definitely resulted in expenditure increase, which probably was the most debatable issue about the project.
\end{abstract}

(Official, Gov. 2)

Increased public cost seems to have reflected poorly on other aspects of the operation phase, such as the criticism to risk allocation, contract management, and dispute management, as further argued by Gov. 2:

\begin{abstract}
We believe that the allocation of market risk was unfair. It should have been more appropriately apportioned to both parties. Additionally, the contract terms offered little space for us to negotiate with the project company, when disputes surfaced.
\end{abstract}

(Official, Gov. 2)

\subsection{Project transfer}

Under the terms of the concession agreement, CGMW would transfer the Chengdu Project to CMG after 15.5 years of operation without further compensation. On 11 August 2015, the transfer committee of the Chengdu Project was set up to facilitate the transfer process. The transfer committee acted in the capacity of a temporary coordinating agency, mandated to facilitate the consent of the public and private parties on the terms of the transfer arrangement. The committee comprised three representatives from the public sector and three from the private sector. On 10 August 2017, only two years after the first transfer committee meeting, a grand transfer ceremony was held on site, marking the official close of the concession period.

The stakeholder satisfaction was achieved in the transfer phase. By contrast with prior phases, the evaluation of the transfer phase received close similar assessments from the two parties. The mean values of the overall evaluation were both above two (2.2 and 2.5) (see Figure 5). This finding means that the transfer phase was regarded as generally highly successful. The success was mainly represented by the complete transfer of numerous items within a limited transition period, as admitted by the respondents from both parties:

They (CGMW) did a good job. More than 180 items of equipment across all its facilities had been thoroughly overhauled, with no less than 800 further items undergoing careful checks prior to transfer.

(Senior manager, CWGC 2)

It was absolutely a successful transfer. According to the signed memorandum, all operational issues arising over the previous two decades had been investigated and resolved over the transfer period.

(Senior manager, CGMW 1)

To complete all these tasks within the limited frame, both sides actively participated in the transfer process. For example, less than one week after the first transfer committee meeting, CMG sent technical experts to the water plant in order to verify the overhaul plan; and CGMW went further, taking the initiative to start the overhaul before it was officially approved. As a result, the stakeholder contribution was achieved in this phase.

Of the three representatives from CMG, the one from the State-owned Assets Supervision and Administration Commission of Chengdu Municipal Government (SASAC-CMG), stood out as dominant. The other two were from the Chengdu Municipal Development and Reform Commission, and the Chengdu Water Authority. However, this personnel arrangement could still be im-

\section{Transfer phase}

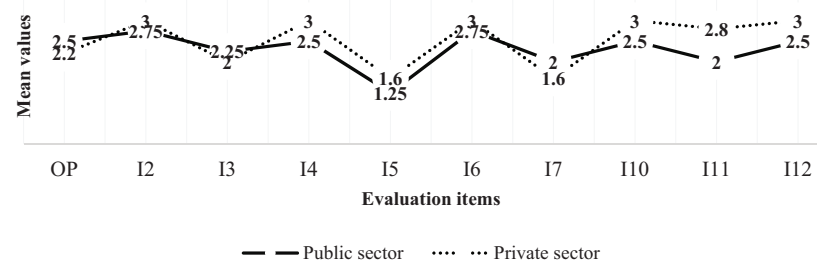

Figure 5. Mean values of the evaluation on project transfer phase Note: OP - Overall performance 
proved for enhanced capacity in dealing with the transfer, as analyzed by CGMW 4:

\begin{abstract}
The problem is that, SASAC-CMG was well experienced at managing state-owned assets. Nonetheless, this one (the Chengdu Project) was a full foreign equity owned company. As a result, some issues outside of the traditional capacities of SASAC-CMG arose in the earlier part of the transfer phase, and this in turn undermined the efficiency of the transfer committee reaching consensus on how to effect the transfer.
\end{abstract}

(Senior manager, CGMW 4)

Among nine process indicators related to the transfer phase, seven (i.e. I2, I3, I4, I6, I10, I11, and I12) were regarded as a success or above by the majority of respondents. These indicators mostly referred to the normal operation of the project. Thus, their success was attributable to factors similar to those found in the operation phase.

Still, two process indicators, namely, I5 or dispute management and I7 or contract management, were assessed as only partly successful, with mean values between one and two (Figure 5). Such evaluation is mainly explained by the intense dispute over the final overhaul plan that arose among the transfer committee members. Specifically, the committee could neither agree on the checklist items, nor on the condition of assets to be overhauled. This dispute reflected two important deficiencies regarding transfer management. First, no established criteria exist for the final overhaul of the water project. In keeping with protecting their own interests, the two parties interpreted requirements in terms favorable to their own positions. Second, the concession agreement offered little help defining standards of the required overhaul. However, this scenario was understandable since the agreement was designed nearly 20 years ago, just as Official Gov. 2 stated:

In my opinion, it was practically impossible for contract designers to forecast precisely, back in the 1990s, what assets would be in place at the time of transfer after 20 years of operation.

(Official, Gov. 1)

\section{Discussion}

\subsection{Summary of the lifecycle performance measurement}

Based on the analysis of the lifecycle evaluations of stakeholders representing various perspectives on the project, plus insights drawn from earlier research, the Chengdu Project can be concluded as generally successful. Its success lies in its efficient project preparation, competitive project procurement, excellent financing, high quality construction, stable operation, and comprehensive transfer back to the public. This conclusion is supported by the evaluative survey results on the project.

The project's success can also be gleaned from the abundant desirable outcomes generated over the project development process. As evidence, the project's contract structure and risk framework over the project preparation phase has been benchmarked by many similar projects that followed (Chen, 2009). Chinese subcontractors and suppliers participating in the construction phase have managed to earn profits while gaining experience in engaging in an international construction project, benefiting from associated technical and managerial knowledge transfers (Han, 2006). Similarly, end-users have enjoyed the supply of sufficient, high quality water throughout the project's concession period. Moreover, the local government benefited from the project by collecting substantial tax receipts.

\subsection{Causes for dissent}

The above analysis indicates that the dissent mainly originated from two key problems: the loss of public benefits due to the inaccurate prediction of water demand in Chengdu and the excessive compromises the public sector was forced to make over various negotiations that occurred. Notwithstanding, a lifecycle analysis reveals that these two problems had complex causes, and that these do not reflect on the PPP procurement process per se or on the Chengdu Project itself.

The singular trigger for the decrease in water demand was a revision in the Chengdu City development plan. The new plan required several industrial companies to move out of the urban area. Notably, these companies collectively consumed a significant proportion of the city's water supply. Compounding the problem, the water distribution network of that time was majorly underdeveloped, and was not connected to those outer regions where those companies relocated. Besides, the forecasting methods by which CMG predicted water demand were also outdated, and this status increased demand forecast error rate over that period (Han, 2006). Under these conditions, loss of public benefits was inevitable, regardless of the financing model adopted in procuring and developing the water plant. Nonetheless, from a lifecycle perspective, the problems caused by decreased water demand lasted for only three years, after which the situation improved with the expansion of the water distribution networks and accompanying water price reforms. As water demand increased, the problem resolved itself. By the end of the 2000s, peak water demand had reached 1.5 million $\mathrm{m}^{3} /$ day, requiring yet another water plant to be built in order to fill the shortfall.

As to the second problem, excessive compromises by CMG during negotiations were more a reflection of Chinass shortages in experience and bargaining power in dealing with international enterprises in the 1990s. Returning to the example of the pipeline thickness dispute, a technical director at CWGC admitted that had this issue been defined more clearly in the bidding documents, the dispute could have been avoided.

\subsection{Recommendations to industry}

In the public utility area of China, the role of PPPs has shifted from the experimentation in the 1990s to becoming the staple means by which infrastructure projects are 
provided to the public. Unfortunately, for some lower tiers of governments, the PPP model is still occasionally perceived as merely a disguised form of borrowing. This situation raised a concern of the central government (Central People's Government of the People's Republic of China, 2017). Most domestic investors who are the current main players in Chinese PPPs still have limited knowledge and experience in developing PPPs. To a certain extent, China currently remains in another new, large-scale experimental stage. Similar to the 1990s, such status requires the management of a considerable amount of uncertainties. Based on the analysis above, the Chengdu Project can provide significant lessons and experiences to better develop PPPs in China's water sector.

First, with PPP project numbers continuing to grow, comprehensive project preparation and competitive procurement procedures should be emphasized. The Chengdu Project took three years to work through all the procedures, from initiating the idea to signing the concession agreement. This was regarded as rather efficient as the project received strong support from the central government and ADB (Chen, 2009). By contrast, in completing the same process for PPP projects in Sichuan province today, where the Chengdu Project is located, only nine months on average are now needed. The fastest case took a mere one month (Roca Consulting, 2017). Given such short periods, determining whether these projects underwent the due diligence and comprehensive preparations necessary to circumvent ambiguities and disputes that may arise down the road remains unclear despite their seeming efficiency.

China's regional governments should further improve the institutional environments in which PPPs develop and operate. Institutions are believed to be closely linked to the healthy promotion of PPPs and foster the industrial culture, legal regimes, and administrative systems required for their promotion (Zhang, Gao, Feng, \& Sun, 2015). The institutional environment in the 1990s under which the Chengdu Project was developed, was thin at best. The high efficiencies achieved came many through special and exceptional approvals from the government in what was seen as a test case, which would now be next to impossible to replicate (Chen, 2009). Therefore, a complete institutional environment is indispensable to achieve high efficiencies. Although a series of policies and regulations with respect to PPP have been vigorously promulgated since 2014, China's institutional environment regarding PPPs remains far from ideal. For instance, apart from low-level guidelines and by-laws, the absence of comprehensive PPP regulations persists. In fact, the two leading departments that hold jurisdiction over PPPs in China, namely, MoF and NDRC, still have not clarified the boundaries of their responsibilities. This ambiguity is accompanied by certain issues being covered by both departments, with occasional contradictory or conflicting regulations. Consequently, some important stakeholders, such as private investors and lenders, have assumed a wait-and-see attitude to PPPs. This scenario excludes important potential players from the market at a time when they are much needed.
Considering the increasing market-oriented character of the water sector and other public utilities in China, the Chinese government, at its various levels, needs to foster independent market players that can represent public interests while protecting their own in line with market rules. In the Chengdu Project, CWGC as the representative of CMG, had not fully expressed its own goals during the project development process, which became one of the key causes of conflicts in the construction and operation phases, and which even lowered the efficiency of the recent transfer phase.

For investors and sponsors alike interested in China's water sector, important insights can be found in the general success of the Chengdu Project. First, foreign investors can have confidence in the credibility of the Chinese government. For a long period, the Chinese government's actions were viewed by the international investors as key political risks detracting from the appeal of the Chinese PPP market (Ke, Wang, Chan, \& Cheung, 2011; Xu et al., 2010). However, CMG's abidance to the terms of the contract throughout the project lifecycle sends a positive signal that the Chinese government does have the capacity to fulfill its contractual obligations and further respect agreements. Remarkably, foreign investors should pay attention to the significant changes related to PPP applications in China. The market has become more competitive now that a great number of domestic enterprises are technologically capable and active in the marketplace. Government thus possesses more bargaining power, and the rewards to contractors may not be as lucrative as those enjoyed by Veolia in the Chengdu Project.

For domestic investors that are not as experienced or capable as their global competitors, finding a complementary partner or establishing consortium like that of the Veolia-Marubeni partnership may be strategically necessary. According to Kumaraswamy, Ling, Anvuur, and Rahman (2007), a suitable consortium team must not only be capable of dealing with hard/technical issues, which is of course primarily essential to the success of PPPs, but also should relationally integrated with other criteria, such as common project objectives, useful mechanism based on and beyond classical contractual practices, and sensitivity to sustainability issues, etc. In China, few large conglomerates possess all those criteria, and thus cooperation between investors remains critical to PPP success.

With respect to the contract management stage, three issues are worthy of particular emphasis under the current circumstance. First, risks in the long operational stage should be well managed. While as a topic risk has drawn significant attention from researchers focusing on the different phases of the PPP life cycle (Bao, Chan, Chen, \& Darko, 2018), analysis on the Chengdu Project empirically proved that maintaining continuous caution on PPP risk is critical. An important reason is that the institutional environment for China's PPP development remains immature, which may lead to unexpected risks (e.g. demand decrease in the Chengdu Project) as policies are frequently changed. Moreover, the water sector per se 
is characterized as sensitive to the natural condition (e.g. extreme weather and environmental pollution), requiring full preparation from practitioners to encounter the risks caused by force majeure. Second, an effective dispute resolution system should be established. Distinct motivations may create disputes between the public and private sectors, especially in the contract management stage, in which over $96 \%$ of disputes appear (Chou, Hsu, Lin, \& Chang, 2016). These disputes are commonly resolved using methods such as negotiation, mediation, arbitration, and litigation (Chou \& Lin, 2012). Unfortunately, a standardized procedure to employ these resolutions effectively to the PPP case remains in its infancy in China. Finally, monitoring the contract compliance of the outputs must be reinforced. Monitoring PPP performance in accordance with concession agreement is one of the major tasks in the contract management stage (EIB, 2012). However, this task has been poorly implemented by the public sectors in many countries owing to reasons, such as measurement complication and inadequate resources and tools (Robinson \& Scott, 2009). As China owns the largest number of PPPs, of which most are actually unknown to the public in terms of their performance, this problem could be significantly critical and thus demands urgent efforts from the entire industry.

\subsection{Implications to the performance measurement of PPPs}

Apart from recommendations to the industry, theoretical implications to the performance measurement of PPPs can also be deduced from the case analysis.

The research results offer empirical support to the necessity of measuring PPPs from multiple perspectives, and more critically, indicating the imperfection of the current frameworks for the performance measurement of PPPs. Although prior research has suggested various measuring frameworks from multiple perspectives (e.g. Liu et al., 2016; Liyanage \& Villalba-Romero, 2015; Liu et al., 2015a; Yuan et al., 2009), their conceptual models have lacked practical validation. By analyzing the Chengdu Project, the PPP performance has been confirmed to vary from different perspectives.

However, the case study also identified several deficiencies of the current frameworks to deal with lifecycle performance. As mentioned previously, a few models have been employed to measure performance in many industries, whereas prior researchers in PPP domain have relied heavily on KPIs model (Liu et al. 2016; Yuan et al., 2009). Despite the advantages possessed by the KPIs model, other potential methods could be explored in PPP domain to cross-check the measurement efficacy of existing ones. In addition, the main technique to establish a quantitative evaluation of KPIs is to gather individuals with relevant expertise to provide a score. This technique requires respondents to possess a profound understanding of or involvement in the project. Otherwise, the viewpoints of the respondents could be biased. Unfortunately, according to the practice of this study, achieving such ideal situation is highly difficult. Moreover, another interesting finding is that, even for one single perspective, a single stakeholder evaluating the performance of a PPP may also be uncertain to some extent. Take the public sector of the Chengdu Project as an example. During the survey process, mixed and occasionally even conflicting feelings on the project can be easily noticed from the representatives of the public sector.

Although many performance factors have been extensively discussed in prior research, the findings of this paper highlight the criticality of assuming a historical angle when evaluating the lifecycle performance of PPPs. Here, historical angle means considering particular historical backgrounds when evaluating past events. Most of the existing research tend to draw conclusion simply by the performance of certain indicators of a project (Raisbeck, Duffield, \& Xu, 2010; Rajan, Gopinath, \& Behera, 2014). However, the reasons behind the performance of a certain indicator have not been emphasized sufficiently. Moreover, PPPs are originally designed to reduce the holistic cost during the entire lifecycle. Consequently, a temporary increase in cost may not seriously influence the project from the considerably long lifecycle perspective, similar to the three-year's increase in the public administrative cost for subsidizing CWGC in the Chengdu Project case.

These abovementioned implications remind the academia that current performance measurement frameworks of PPPs are still preliminary, incapable of comprehensively and precisely capturing the genuine performance of a complicated PPP. Thus, precise and reliable measurement frameworks, as well as empirical studies are urgently required.

\section{Conclusions}

After nearly 30 years of development, China has built an extraordinary number of PPP infrastructure projects. However, little is known of the project performance of these existing PPPs. Such paucity hinders the attempt to draw best practices from those numerous cases to improve management strategies and facilitate future developments of PPPs in China. By contrast, the performance measurement of PPPs has been studied by a few prior studies that proposed several frameworks for measuring PPP performance. Nevertheless, the effectiveness of those frameworks requires further validation via empirical evidence.

To fill the gaps in practical and theoretical terms, this paper conducted an in-depth case study on the Chengdu Project, which has been transferred to the government on 10 August 2017 after 18 years of operation. This chosen case notably became the first and only water PPP completing the entire concession period in China. Performing the case analysis required using a triangulation method, including literature review, archival analysis, questionnaire survey, and post-survey interview. The cross-checking approaches provided comprehensive sources for data collection, based on which, qualitative and quantitative analyses were conducted. 
The findings of this paper, including earlier results regarding the Chengdu Project from literature, confirm the success of the Chengdu Project from a lifecycle perspective. This claim was based on multiple pieces of evidence, focusing on both the main stakeholders' understanding of the project and absorbing objective archival data. Moreover, the authors discussed the reasons for dissent between stakeholders' various evaluations by relating the project to particular historical backgrounds. Considering China's current stage of evolution in the PPP development, recommendations to the industry and implications to performance measurement theory were offered on the basis of the lessons and experiences drawn from the Chengdu Project.

The outcomes of this paper fulfill the three research objectives. PPP participants in China can gather lessons from this research, irrespective of their role or relationship regarding PPPs. Moreover, researchers can find inspiration in this paper to identify and resolve particular problems hampering the development of PPPs in China and to improve the ongoing research on the performance measurement of PPPs.

\section{Acknowledgments}

This research is part of a Joint $\mathrm{PhD}$ Programme leading to Dual Awards (PhD of the Hong Kong Polytechnic University and Doctorate Degree of Sichuan University) which is supported by the Hong Kong Jockey Club.

\section{References}

ADB. (2006). Guidelines for preparing performance evaluation reports for public sector operations. Retrieved from https://www. adb.org/sites/default/files/institutional-document/32516/ guidelines-evaluation-public-sector.pdf

ADB. (2008). Public-private partnerships handbook. Philippines: ADB.

Ansar, A., Flyvbjerg, B., Budzier, A., \& Lunn, D. (2016). Does infrastructure investment lead to economic growth or economic fragility? Evidence from China. Oxford Review of Economic Policy, 32(3), 360-390. https://doi.org/10.1093/oxrep/grw022

Atkinson, R. (1999). Project management: cost, time and quality, two best guesses and a phenomenon, its time to accept other success criteria. International Journal of Project Management, 17(6), 337-342. https://doi.org/10.1016/S0263-7863(98)00069-6

Bao, F., Chan, A. P. C., Chen, C., \& Darko, A. (2018). Review of public-private partnership literature from a project life cycle perspective. Journal of Infrastructure Systems, 24(3).

https://doi.org/10.1061/(ASCE)IS.1943-555X.0000424

Bassioni, H. A., Price, A. D. F., \& Hassan, T. M. (2004). Performance measurement in construction. Journal of Management in Engineering, 20(2), 42-50.

https://doi.org/10.1061/(ASCE)0742-597X(2004)20:2(42)

Bititci, U. S., Carrie, A. S., \& McDevitt, L. (1997). Integrated performance measurement systems: a development guide. International Journal of Operations \& Production Management, 17(5), 522-534. https://doi.org/10.1108/01443579710167230

Central People's Government of the People's Republic of China. (2017). Circular on further regulating the behavior of local government borrowing for financing. Retrieved from http://www. gov.cn/xinwen/2017-05/03/content_5190675.htm
Chan, A. P. C., \& Chan, A. P. L. (2004). Key performance indicators for measuring construction success. Benchmarking: An International Journal, 11(2), 203-221.

https://doi.org/10.1108/14635770410532624

Chan, A. P. C., Darko, A., \& Ameyaw, E. E. (2017). Strategies for promoting green building technologies adoption in the construction industry - an international study. Sustainability, 9(6), 969. https://doi.org/10.3390/su9060969

Chen, C. (2009). Can the pilot BOT Project provide a template for future projects? A case study of the Chengdu No. 6 Water Plant B Project. International Journal of Project Management, 27(6), 573-583. https://doi.org/10.1016/j.ijproman.2008.10.006

Chen, C., \& Doloi, H. (2008). BOT application in China: driving and impeding factors. International Journal of Project Management, 26(4), 388-398. https://doi.org/10.1016/j.ijproman.2007.07.002

Cheng, Z., Ke, Y., Lin, J., Yang, Z., \& Cai, J. (2016). Spatio-temporal dynamics of public private partnership projects in China. International Journal of Project Management, 34(7), 12421251. https://doi.org/10.1016/j.ijproman.2016.05.006

Cheung, E., \& Chan, A. P. (2009). Is BOT the best financing model to procure infrastructure projects? A case study of the Hong Kong-Zhuhai-Macau Bridge. Journal of Property Investment \& Finance, 27(3), 290-302.

https://doi.org/10.1108/14635780910951984

Chou, J.-S., \& Lin, C. (2012). Predicting disputes in public-private partnership projects: classification and ensemble models. Journal of Computing in Civil Engineering, 27(1), 51-60. https://doi.org/10.1061/(ASCE)CP.1943-5487.0000197

Chou, J. S., Hsu, S. C., Lin, C. W., \& Chang, Y. C. (2016). Classifying influential for project information to discover rule sets for project disputes and possible resolutions. International Journal of Project Management, 34(8), 1706-1716.

Cruz, C. O., Marques, R. C., \& Pereira, I. (2015). Alternative contractual arrangements for urban light rail systems: lessons from two case studies. Journal of Construction Engineering and Management, 141(3).

https://doi.org/10.1061/(ASCE)CO.1943-7862.0000942

Dayue Consulting. (2014). The world bank PPP unit visit Dayue. Retrieved from http://www.dayue.com/templates/T_Second/ index.aspx ? contentid $=2302$ \&nodeid $=50$ \&page $=$ ContentPage

EIB. (2012). The guide to guidance: how to prepare, procure and deliver PPP projects. Retrieved from http://www.eib. org/attachments/epec/epec_the_guide_to_guidance_en.pdf?f $=$ search $\&$ media $=$ search

El-Gohary, N. M., Osman, H., \& El-Diraby, T. E. (2006). Stakeholder management for public private partnerships. International Journal of Project Management, 24(7), 595-604. https://doi.org/10.1016/j.ijproman.2006.07.009

Gerring, J. (2007). Is there a (viable) crucial-case method? Comparative Political Studies, 40(3), 231-253. https://doi.org/10.1177/0010414006290784

Hall, D., Lobina, E., \& Terhorst, P. (2013). Re-municipalisation in the early twenty-first century: water in France and energy in Germany. International Review of Applied Economics, 27(2), 1-6. https://doi.org/10.1080/02692171.2012.754844

Ham, H. V., \& Koppenjan, J. (2001). Building public-private partnerships: assessing and managing risks in port development. Public Management Review, 3(4), 593-616. https://doi.org/10.1080/14616670110070622

Han, Y. (2006). Research on the BOT financing mode of Chengdu No. 6 water plant B project. University of Electronic Science and Technology of China.

Henjewele, C., Sun, M., \& Fewings, P. (2014). Comparative performance of healthcare and transport PFI projects: empirical 
study on the influence of key factors. International Journal of Project Management, 32(1), 77-87.

https://doi.org/10.1016/j.ijproman.2013.01.008

HM Treasury. (2004). Regularity, propriety and value for money. London, UK: HM Treasury.

HM Treasury. (2008). Infrastructure procurement: delivering longterm value. UK Government.

HM Treasury. (2013a). Making savings in operational PFI contracts. London, UK: HM Treasury.

HM Treasury. (2013b). PFI/PPP finance guidance. Retrieved from https://www.gov.uk/government/publications/pfipppfinance-guidance

HM Treasury. (2016). PFI/PF2/PPP forms. London, UK: HM Treasury.

Hodge, G. A. (2004). The risky business of public-private partnerships. Australian Journal of Public Administration, 63(4), 37-49. https://doi.org/10.1111/j.1467-8500.2004.00400.x

Hodge, G. A., \& Greve, C. (2007). Public-private partnerships: an international performance review. Public Administration Review, 67(3), 545-558.

https://doi.org/10.1111/j.1540-6210.2007.00736.x

Holmes, J., Capper, G., \& Hudson, G. (2006). Public private partnerships in the provision of health care premises in the UK. International Journal of Project Management, 24(7), 566-572. https://doi.org/10.1016/j.ijproman.2006.07.004

Jefferies, M. (2006). Critical success factors of public private sector partnerships: a case study of the Sydney SuperDome. Engineering, Construction and Architectural Management, 13(5), 451-462. https://doi.org/10.1108/09699980610690738

Kagioglou, M., Cooper, R., \& Aouad, G. (2001). Performance management in construction: a conceptual framework. Construction Management and Economics, 19(1), 85-95. https://doi.org/10.1080/01446190010003425

Ke, Y., Wang, S., Chan, A. P. C., \& Cheung, E. (2011). Understanding the risks in China's PPP projects: ranking of their probability and consequence. Engineering, Construction and Architectural Management, 18(5), 481-496.

https://doi.org/10.1108/09699981111165176

Kumaraswamy, M. M., Ling, F. Y. Y., Anvuur, A. M., \& Rahman, M. M. (2007). Targeting relationally integrated teams for sustainable PPPS. Engineering, Construction and Architectural Management, 14(6), 581-596.

https://doi.org/10.1108/09699980710829030

Leiringer, R., \& Schweber, L. (2010). Managing multiple markets: big firms and PFI. Building Research \& Information, 38(2), 131-143. https://doi.org/10.1080/09613210903027147

Liu, J., Love, P. E. D., Davis, P. R., Smith, J., \& Regan, M. (2015a). Conceptual framework for the performance measurement of public-private partnerships. Journal of Infrastructure Systems, 21(1). https://doi.org/10.1061/(ASCE)IS.1943-555X.0000210

Liu, J., Love, P. E. D., Smith, J., Matthews, J., \& Sing, C. P. (2016). Praxis of performance measurement in public-private partnerships: moving beyond the iron triangle. Journal of Management in Engineering, 32(4).

https://doi.org/10.1061/(ASCE)ME.1943-5479.0000433.

Liu, J., Love, P. E. D., Smith, J., Regan, M., \& Palaneeswaran, E. (2015b). Review of performance measurement: implications for public-private partnerships. Built Environment Project and Asset Management, 5(1), 35-51.

https://doi.org/10.1108/BEPAM-12-2013-0070

Liyanage, C., \& Villalba-Romero, F. (2015). Measuring success of PPP transport projects: a cross-case analysis of toll roads. Transport Reviews, 35(2), 140-161. https://doi.org/10.1080/0 1441647.2014.994583
MOF. (2014). Circular on the issuance of public-private partnership mode operation guide (trial).

Neely, A. (1999). The performance measurement revolution: why now and what next? International Journal of Operations \& Production Management, 19(2), 205-228. https://doi.org/10.1108/01443579910247437

Neely, A., Adams, C., \& Crowe, P. (2001). The performance prism in practice. Measuring Business Excellence, 5(2), 6-13(18). https://doi.org/10.1108/13683040110385142

Neely, A., Adams, C., \& Kennerley, M. (2002). The performance prism: the scorecard for measuring and managing business success. Financial Times Prentice Hall.

Osei-Kyei, R., Chan, A. P. C., Javed, A. A., \& Ameyaw, E. E. (2017). Critical success criteria for public-private partnership projects: international experts' opinion. International Journal of Strategic Property Management, 21(1), 87-100. https://doi.org/10.3846/1648715X.2016.1246388

People's Daily Online. (2000). Chengdu is in urgent need of water. Retrieved from http://www.people.com.cn/GB/channel4/27/20000724/156479.html

Pollock, A. M., Price, D., \& Player, S. (2007). An examination of the UK treasury's evidence base for cost and time overrun data in UK value-for-money policy and appraisal. Public Money \& Management, 27(2), 127-134.

https://doi.org/10.1111/j.1467-9302.2007.00568.x

PricewaterhouseCoopers. (2010). Public_private_partnerships: The US perspective. Las Vegas, NV: PricewaterhouseCoopers LLP.

Raisbeck, P., Duffield, C., \& Xu, M. (2010). Comparative performance of PPPs and traditional procurement in Australia. Construction Management and Economics, 28(4), 345-359. https://doi.org/10.1080/01446190903582731

Rajan, T. A., Gopinath, G., \& Behera, M. (2014). PPPs and project overruns: evidence from road projects in India. Journal of Construction Engineering and Management, 140(5). https://doi.org/10.1061/(ASCE)CO.1943-7862.0000797

Robinson, H. S., \& Scott, J. (2009). Service delivery and performance monitoring in PFI/PPP projects. Construction Management and Economics, 27(2), 181-197. https://doi.org/10.1080/01446190802614163

Roca Consulting. (2017). Overview of PPP projects and analysis of PPP index in Sichuan Province. Chengdu, Roca Consulting.

Şentürk, H. A., Yazici, G., \& Kaplanoğlu, S. B. (2004). Case study: Izmit domestic and industrial water supply build-operatetransfer project. Journal of Construction Engineering and Management, 130(3), 449-454.

https://doi.org/10.1061/(ASCE)0733-9364(2004)130:3(449)

Shen, L.-Y., Platten, A., \& Deng, X. (2006). Role of public private partnerships to manage risks in public sector projects in Hong Kong. International Journal of Project Management, 24(7), 587-594. https://doi.org/10.1016/j.ijproman.2006.07.006

Sobhiyah, M. H., Bemanian, M. R., \& Kashtiban, Y. K. (2009). Increasing VFM in PPP power station projects - case study: Rudeshur gas turbine power station. International Journal of Project Management, 27(5), 512-521.

https://doi.org/10.1016/j.ijproman.2008.07.002

Talbot, C. (2010). Theories of performance: organizational and service improvement in the public domain (1st ed.). Oxford: Oxford University Press.

Tiong, R. L. K. (1990). Comparative study of BOT projects. Journal of Management in Engineering, 6(1), 107-122. https://doi.org/10.1061/(ASCE)9742-597X(1990)6:1(107)

Vaismoradi, M., Turunen, H., \& Bondas, T. (2013). Content analysis and thematic analysis: implications for conducting a 
qualitative descriptive study. Nursing \& Health Sciences, 15(3), 398-405. https://doi.org/10.1111/nhs.12048

Victoria State Government. (2017). Partnerships Victoria-Excellence in public private partnerships. Retrieved from http:// www.dtf.vic.gov.au/Infrastructure-Delivery/Public-privatepartnerships/Partnerships-Victoria-Excellence-in-publicprivate-partnerships

Wang, S. Q., \& Tiong, L. K. (2000). Case study of government initiatives for PRC's BOT power plant project. International Journal of Project Management, 18(1), 69-78. https://doi.org/10.1016/S0263-7863(98)00072-6

Wang, S. Q., Tiong, R. L. K., Ting, S. K., Chew, D., \& Ashley, D. (1998). Evaluation and competitive tendering of BOT power plant project in China. Journal of Construction Engineering and Management, 124(4), 333-341.

https://doi.org/10.1061/(ASCE)0733-9364(1998)124:4(333)

Ward, S., Curtis, B., \& Chapman, C. (1991). Objectives and performance in construction projects. Construction Management and Economics, 9(4), 343-353. https://doi.org/10.1080/01446199100000027

World Bank. (2014). Public-private partnerships reference guide v2.0. Retrieved from http://www-wds.worldbank.org/external/default/WDSContentServer/WDSP/IB/2014/09/08/0004 42464_20140908133431/Rendered/PDF/903840PPP0Refe0B ox385311B000PUBLIC0.pdf

Wu, J., Liu, J., Jin, X., \& Sing, M. C. P. (2016). Government accountability within infrastructure public-private partner- ships. International Journal of Project Management, 34(8), 1471-1478. https://doi.org/10.1016/j.ijproman.2016.08.003

Xu, Y., Yeung, J. F. Y., Chan, A. P. C., Chan, D. W. M., Wang, S. Q., \& Ke, Y. (2010). Developing a risk assessment model for PPP projects in China - a fuzzy synthetic evaluation approach. Automation in Construction, 19(7), 929-943. https://doi.org/10.1016/j.autcon.2010.06.006

Yang, H., Yeung, J. F. Y., Chan, A. P. C., Chiang, Y. H., \& Chan, D. W. M. (2010). A critical review of performance measurement in construction. Journal of Facilities Management, 8(4), 269-284. https://doi.org/10.1108/14725961011078981

Yuan, J., Yajun Zeng, A., Skibniewski, M. J., \& Qiming, L. I. (2009). Selection of performance objectives and key performance indicators in public-private partnership projects to achieve value for money. Construction Management and Economics, 27(3), 253-270. https://doi.org/10.1080/01446190902748705

Zhang, S., Chan, A. P. C., Feng, Y., Duan, H., \& Ke, Y. (2016). Critical review on PPP research - a search from the Chinese and International Journals. International Journal of Project Management, 34(4), 597-612. https://doi.org/10.1016/j.ijproman.2016.02.008

Zhang, S., Gao, Y., Feng, Z., \& Sun, W. (2015). PPP application in infrastructure development in China: institutional analysis and implications. International Journal of Project Management, 33(3), 497-509. https://doi.org/10.1016/j.ijproman.2014.06.006 